\title{
Perceptions of tourism: a study of residents' attitudes towards tourism in the city of Girona
}

\author{
Sira Vidal Rua \\ Department of Organisation, Business Management and Product Design, \\ University of Girona, Girona, Spain
}

\begin{abstract}
Purpose - Socio-cultural impacts of tourism have been widely researched within a social exchange theoretical framework, yet it seems that this theory could be neglecting those more emotional elements, which at the same time could be considered key to understand how tourism affects the society. Therefore, the purpose of this paper is to look at the social exchange theory (SET) from a different perspective and focus on those less rational influencing factors that could be shaping residents' attitudes towards tourism.

Design/methodology/approach - Based on six main constructs, a quantitative survey-based research is developed in the small city of Girona with the purpose to broaden the versality of the theory, with the support of in-depth exploratory interviews. Thus, an exhaustive study of the influences that attachment to communities, involvement in the tourism industry and personal benefits derived from tourism could have on residents' perceptions is developed.

Findings - This paper suggests that those smaller tourism destinations might mirror themselves in those close big tourism destinations and thus residents' opinions and attitudes seem to be influenced by the situations lived in these larger tourism destinations. Moreover, this paper stresses on the importance of interactions and relationships between tourists and residents to boost personal benefits from tourism. Finally, results show how those attached citizens tend to support tourism development, which could be explained by the proudness they feel when others value what for them is home.

Originality/value - This paper contributes to the current understanding of attitudes towards tourism within the SET framework, especially relating to covering those more emotional elements of social interactions. Moreover, there seems to be a gap in current research relating to small urban destinations that is aimed to be covered in this research.
\end{abstract}

Keywords Perceptions, Tourism, Attitudes, Social exchange theory, Residents,

Socio-cultural impacts

Paper type Research paper

\section{Introduction}

Tourism is proven to be crucial for the global economic development (World Tourism Organization, 2018; World Travel and Tourism Council, 2018), yet it is a very transversal industry that affects not only the economy of a destination but also its environment, its society and its culture. This paper focusses on those socio-cultural aspects of tourism as it

(c) Sira Vidal Rua. Published in Journal of Tourism Analysis: Revista de Análisis Turístico. Published by Emerald Publishing Limited. This article is published under the Creative Commons Attribution (CC BY 4.0) licence. Anyone may reproduce, distribute, translate and create derivative works of this article (for both commercial and non-commercial purposes), subject to full attribution to the original publication and authors. The full terms of this licence may be seen at http://creativecommons.org/ licences/by/4.0/legalcode

Funding: This work was supported by the Girona City Council.

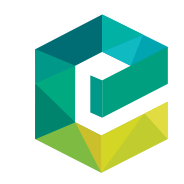

Journal of Tourism Analysis: Revista de Análisis Turístico Vol. 27 No. 2, 2020 pp. 165-184
Emerald Publishing Limited Emerald Publishing Limited
2254-064 DOI 10.1108/JTA-03-2019-0015 
aims at contributing to generate knowledge on the resident's perceptions of tourism. While "host" communities are expected to offer a friendly welcome, this hospitality could be turning into hostility in some tourism destinations (Pizam, 1978; Deery et al., 2012), which is rather distinguished by unfriendly behaviours. Therefore, knowledge on residents' perceptions is relevant for both the well-being of the local communities (Gursoy and Rutherford, 2004; Andereck et al., 2007) and for the development of tourism in a sustainable manner (Deery et al., 2012; Williams and Lawson, 2001).

Social exchange theory (here and after referred to as SET) has been the theoretical framework base of most of the studies on relations between tourism and local communities (Andereck et al., 2005; Deery et al., 2012). This theory states that in any interaction, there will be an exchange of resources only if individuals perceive that they will gain something from it (Gursoy and Rutherford, 2004; Andereck et al., 2005). However, this theory has been criticized (Andereck et al., 2005) for focusing mainly on mere cognitive and rational elements of transactions between residents and tourists. A key rational for doing this research is the thought that there could be far more aspects to be considered to understand local communities' attitudes towards tourism than what is considered within SET's rational perspective. Other researchers (Boley et al., 2014; Moscardo, 2011; Williams and Lawson, 2001) seem to have had similar thoughts, as they aim at turning the attention away from rational transactions towards how locals feel and think regarding tourism.

While some authors argue that research on attitudes towards tourism is overly done in rural areas (Gursoy et al., 2002), the importance of urban tourism in European cities has not ceased since the 1990's (Law, 1992; Valls et al., 2014). While the global tourism increase rate was of 7 per cent (World Tourism Organization, 2018) from 2017 to 2018, tourism in European cities increased by 7.5 per cent (European Cities Marketing, 2018). The fact that urban tourism is that widespread is peculiarly contrasted with the current emphasis given by researchers to rural areas, which stresses the need for developing more studies in urban contexts.

The role of low-cost airlines has been key, as they not only have enabled short trips or city breaks across Europe (Valls et al., 2014; Bellini and Pasquinelli, 2017), but they have also raised awareness of the existence of less popular cities, which expands and distributes tourists across the continent (Dunne et al., 2007). Even though dissemination of tourism throughout smaller cities can bring many benefits, it also raises concerns due to high concentrations of tourism activities in confined spaces. The arousal of manifestations of discomfort (such as anti-tourism marches) have instigated governments to launch policies to better regulate tourism in destinations such as Mallorca and San Sebastian in Spain, Dubrovnik in Croatia, or Florence in Italy (Coldwell, 2017; Kettle, 2017). Strategic plans for tourism are being applied in some tourism destinations, which could be considered as a good starting point towards a more sustainable management. Yet, there seems to be still space for these measures to go beyond "dealing with" the problems caused by tourism, as it seems that, at least some of them, could be prevented. Hence, a shift towards identifying which are the possible causes for social unrests could be a good next step to prevent these discomforts.

Considering that understanding how residents perceive tourism may facilitate a more proactive tourism planning and management decisions (Tovar and Lockwood, 2008; Deery et al., 2012), this paper aims to contribute to a deeper understanding of some of the possible reasons of residents' attitudes in a medium/small city towards tourism.

With this purpose, this research is developed in Girona, which is a small city located in the north-east of Spain, the second country in the world with more international arrivals (World Travel Organization, 2018; p. 8) and one of the countries most affected by clashes between residents and tourists (Burgen, 2017a, 2017b; Coldwell, 2017; Kettle, 2017). With 
100,266 inhabitants (Instituto Nacional de Estadística, 2018)[1], Girona is the capital of the province, named after the city, known for its beaches in Costa Brava. Even though Girona does not suffer from major conflicts between residents and tourism, some voices of concern are raised in the city and few banners showing discomfort with the tourism activity have appeared in the city centre (Carreras and Pastells, 2017; Pastells, 2017).

These manifestations can be considered as an evidence of changing attitudes towards tourism, which makes one question why this might be happening, especially if these attitudes become negative. To this end, the following research question is formulated:

Tourism in the city of Girona

$R Q 1$. How do residents of Girona perceive tourism? And what are the possible reasons behind these perceptions?

Considering that attitudes constantly evolve and that they are not always rational, the purpose of this research is not to give a final list of reasons why residents might hold one attitude or another, but to develop a deeper understanding on elements related to tourism that are more likely to have an impact on them. Moreover, the research will contribute in expanding the existing literature on SET, as it intends to include non-transactional elements such as moral values and emotions that may influence locals' attitudes.

\section{Theoretical framework}

As it will be discussed in the methodology section, this research is conceived as a quantitative survey-based research supported by qualitative interviews. The quality of surveys depends not only on the adequate numbers of respondents, but also on the extent to which the questionnaire measures the most appropriate concepts in the best possible way (validity). This is one of the reasons why quantitative research tends to prioritize being strongly supported by theory over covering a wide range of relevant research topics (Walle, 1997). Thus, it was considered imperative to minimize the number of concepts and constructs covered to achieve a duly theoretically grounded questionnaire.

This approach could be defined as reductionist. Reductionism is defined as a "viewpoint that regards one phenomenon as entirely explainable by the properties of another phenomenon" (Ratner, 2012). Following this line of thought, it is pursued to investigate how few very carefully selected constructs contribute to generate knowledge about how attitudes towards tourism are formed. Therefore, the questionnaire is based on six constructs that, based on literature reviews and on in-depth interviews, are considered the most relevant elements influencing Girona residents' attitudes towards tourism development. Figure 1 outlines which constructs are considered to have greater explanatory power and the relationships expected to be found between each other. Due to the reductionistic approach undertaken, only the variables included in Figure 1 are subject to analysis.

Tourism developers seek to boost support for tourism because it is essential for a sustainable tourism development (Tosun, 2002; Gursoy and Rutherford, 2004; Deery et al., 2012). Following the premise of SET, support towards tourism should be the result of weighting the benefits and costs derived from the activity. Therefore, in this research it is considered that perceived benefits from tourism and perceived costs from tourism directly influence residents' support towards it. Support for tourism was analysed using a scale adapted from Nunkoo and So (2016), as it can be seen in Table I.

Perceived negative impacts of tourism are considered "costs" within the SET framework, and thus both terms are used interchangeably in this article. According to SET, the negative impacts perceived from tourism will have a negative influence on their support towards the industry. Several authors have examined these relationships (Perdue et al., 1990; Jurowski et al., 1997; Gursoy et al., 2002; Gursoy and Rutherford, 2004; Nunkoo and So, 2016), yet 


\section{8}

Figure 1.

Expected

relationships between constructs

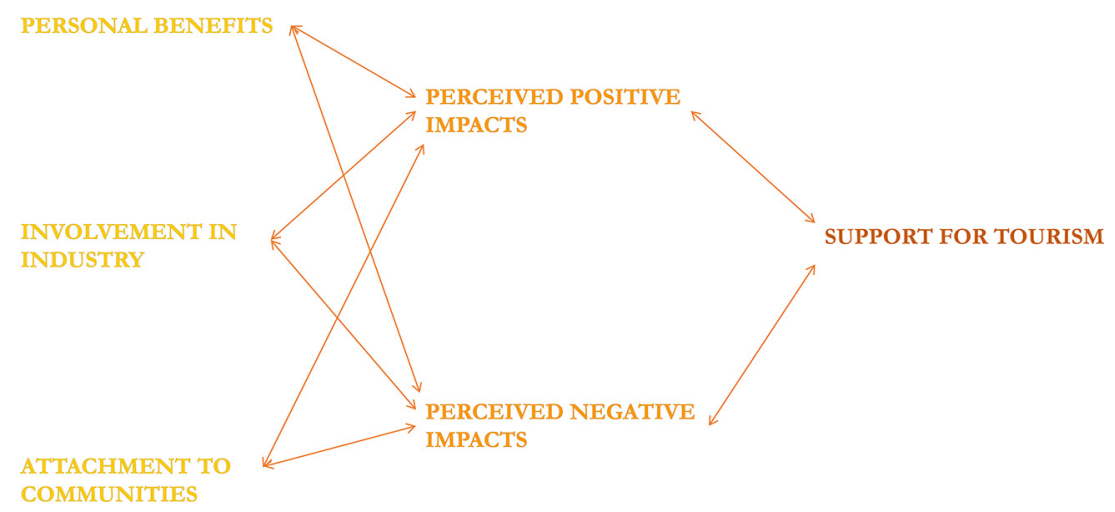

many with not so conclusive results. While academics have found negative causal relationships between these two variables, they were not statistically significant (Gursoy et al., 2002; Gursoy and Rutherford, 2004; Nunkoo and So, 2016; Su et al., 2018). To measure perceived negative impacts, the questionnaire includes questions relating to the increased prices of housing (Jurowski et al., 1997; Tovar and Lockwood, 2008); the increased prices of goods and services (Gursoy and Rutherford, 2004; Jurowski et al., 1997; Nunkoo and So, 2016); the pedestrian congestions (Brunt and Courtney, 1999; Lindberg and Johnson, 1997; McCool and Lime, 2001); the increased noise (Andereck et al., 2005; Brunt and Courtney, 1999; Gursoy and Rutherford, 2004); the increased pollution (Gursoy et al., 2002; Andereck et al., 2005); and the changes in the physical appearance of the city (Lindberg and Johnson, 1997).

Following the same line of thought as for the perceived negative impacts from tourism, SET implies that the perceived positive impacts from tourism will positively influence their support towards it. In the same way as the term "costs" is used to refer to perceived negative impacts, the term "benefits" is also used to refer to perceived positive impacts of tourism along this paper. Significant causal relationships between perceived benefits of tourism and support towards have been found by several authors (Gursoy et al., 2002; Gursoy and Rutherford, 2004; Jurowski et al., 1997; Nunkoo and So, 2016), which seems to contrast with the non-significant relationships found between the negative impacts of tourism and support towards the industry. Benefits of tourism were examined through residents' perceptions on increased employment (Gursoy et al., 2002; Jurowski et al., 1997), or on increased business opportunities (Gursoy and Rutherford, 2004; Nunkoo and So, 2016). In addition, questions relating to the improved appearance of the city thanks to tourism (Andereck et al., 2005; Perdue et al., 1990), the increased leisure opportunities due to tourism (Brunt and Courtney, 1999; Gursoy et al., 2002), or the increased opportunities for socializing (Andereck et al., 2005; Gursoy and Rutherford, 2004; Jurowski et al., 1997) were included in the questionnaire.

This research also analyses the influence that personal benefits from tourism, involvement in tourism, and attachment to communities might have on the perceived impacts of tourism. Regarding personal benefits, several authors (Andereck et al., 2005; Jurowski et al., 1997; Lankford and Howard, 1994; Nunkoo and So, 2016) have analysed the relationships that they have with perceived impacts from the industry. Most studies have found positive and significant relationships between personal benefits and perceived positive impacts from tourism (Andereck et al., 2005; Brunt and Courtney, 1999; Nunkoo and So, 2016). Economic 


\begin{tabular}{|c|c|c|}
\hline Variables & Indicators & th \\
\hline Support for tourism & $\begin{array}{l}\text { Tourism is one of the most important industry for my community } \\
\text { Tourism helps my community grow } \\
\text { Tourism helps my community grow in the right direction } \\
\text { Tourism plays an important economic role in my community } \\
\text { I am proud that tourists are coming to my community } \\
\text { I support the development of tourism as it is vital to my community } \\
\text { My community should try to attract more tourists }\end{array}$ & 169 \\
\hline $\begin{array}{l}\text { Perceived negative } \\
\text { impacts from tourism }\end{array}$ & $\begin{array}{l}\text { Increased prices of goods and services } \\
\text { Increased prices of rents } \\
\text { Increased noises } \\
\text { Increased congestions } \\
\text { Arousal of souvenir shops and cafes aimed at tourists instead of establishments } \\
\text { aimed at locals }\end{array}$ & \\
\hline $\begin{array}{l}\text { Perceived positive } \\
\text { impacts from tourism }\end{array}$ & $\begin{array}{l}\text { Increased employment opportunities for locals } \\
\text { Increased opportunities for local businesses } \\
\text { Improved appearance of the city } \\
\text { Increased opportunities for leisure } \\
\text { Increased opportunities for socializing }\end{array}$ & \\
\hline Attachment to community & $\begin{array}{l}\text { Length of residence } \\
\text { Feelings of moving away } \\
\text { Feeling of being "at home" } \\
\text { Interest on what is going on }\end{array}$ & \\
\hline $\begin{array}{l}\text { Involvement in the } \\
\text { tourism industry }\end{array}$ & $\begin{array}{l}\text { Level of knowledge about tourism development in Girona } \\
\text { Level of knowledge about tourists in Girona } \\
\text { Level of knowledge on tourism impacts } \\
\text { Development of friendship with tourists } \\
\text { Frequency of visitation to tourism areas } \\
\text { Involvement in decision-making process }\end{array}$ & \\
\hline $\begin{array}{l}\text { Personal benefits from } \\
\text { tourism }\end{array}$ & $\begin{array}{l}\text { Meet more people and learn from other cultures } \\
\text { There are more bars and restaurants I can go to } \\
\text { Employed thanks to tourism } \\
\text { Tourism contributes to household income }\end{array}$ & $\begin{array}{l}\text { Table I. } \\
\text { Variables and } \\
\text { indicators }\end{array}$ \\
\hline
\end{tabular}

personal benefits were analysed by examining the degree to which respondents' household income came from tourism (Andereck et al., 2005; Jurowski et al., 1997) and if they were directly employed by the tourism industry (Lankford and Howard, 1994). However, those non-economic personal benefits from tourism were more difficult to describe:

- first, because they refer to more emotional elements; and

- second because the line between benefits for the community and personal benefits can be blurry.

In fact, some interviewees did not even consider they could personally benefit from tourism in a non-economic manner. In addition, literature seems vague when it comes to describing non-economic personal benefits. While many authors have examined self-reported personal benefits of tourism (Nunkoo and So, 2016; Perdue et al., 1990; Andereck et al., 2005) it seemed more accurate to describe the concrete gains that one can obtain from the industry. Based on the interviews, it seemed interesting to analyse whether residents perceive that they personally benefit from more leisure opportunities thanks to tourism, as well as if they perceive that they personally have more opportunities to learn from other cultures thanks to tourism. 
On the other hand, involvement in the tourism industry is a very complex and broad concept. Andereck et al. (2005) suggest that engagement with the tourism industry could be assessed through the following variables: the level of knowledge about tourism, the level of contact with tourists, the degree of involvement in decision-making processes, and the distance of residents' home from the tourism centre. This study attempted to measure involvement in the tourism industry through these variables, excluding the distance of residents' home from the tourism centre as it was included in the questionnaire as a demographic question. Following this line of thought, the first variable within involvement in the tourism industry is knowledge about tourism, which has been studied by several authors (Davis et al., 1988; Lankford and Howard, 1994; Andereck et al., 2005; Nunkoo and So, 2016). However, while some authors (Davis et al., 1988) found that those less knowledgeable were the less supportive, others (Nunkoo and So, 2016) found the opposite. These discrepancies are not surprising since there seems to be no standardized measure of knowledge, and the usage of different scales makes it difficult to compare results among studies. For the purpose of this research, the scale to measure knowledge was adapted from Nunkoo and So (2016), as it can be seen in Table I.

In relation to the level of involvement in the tourism decision-making process, several studies (Lankford and Howard, 1994; Andereck et al., 2005, 2007; Nunkoo and So, 2016; Lankford and Howard, 1994; Andereck et al., 2005, 2007; Nunkoo and So, 2016) found that those citizens more involved in the tourism industry perceive more positive impacts from tourism than those who are not. These findings suggest that more participative approaches from local governments could help raise and maintain more positive attitudes towards tourism. Girona City Hall seems to be very aware of this and seems to be making efforts to involve communities in the decision-making process, yet some interviewees felt that their opinions were being asked but not listened to. Additionally, the level of contact with tourists has been found to be positively related with being more supportive towards tourism development (Andereck et al., 2005; Kayat, 2002; Lankford and Howard, 1994). Table I shows the scale used to measure this construct that is adapted from Lankford and Howard (1994). In sum, it is expected that those residents more involved in the tourism industry would perceive more benefits from the industry and hence, be more supportive.

Finally, several academics have shown interest in understanding the influence that attachment to communities might have on the residents' perceptions of tourism impacts, and ultimately, on their support for it (Andereck et al., 2005; McCool and Martin, 1994; Williams and Lawson, 2001). Even though some authors suggest that those citizens more attached to their communities will perceive less benefits from tourism (Lankford and Howard, 1994); others advocate that those more attached will perceive more benefits (Pizam, 1978; Jurowski et al., 1997; Gursoy et al., 2002; Gursoy and Rutherford, 2004). Based on the exploratory interviews, the latter should be expected within Girona residents. As it can be seen in Table I, the questionnaire adapts the scale used by several researchers (McCool and Martin, 1994; Gursoy et al., 2002; Gursoy and Rutherford, 2004) to analyse attachment to communities, as it is considered as an accurate scale of measurement.

\section{Methodology}

This research is guided by a post-positivism standpoint. Hence, it is acknowledged that reality exists but cannot be known in a perfect manner (critical realism) and that, even if the researcher aims at being objective, there can always be uncontrolled interferences between what is analysed and the researcher (modified objectivism), which will inevitably lead to some degree of subjectivism. Following this line of thought, it is acknowledged that not all the variables can be controlled, and hence, the methodological standpoint guiding this 
research is the modified/manipulative. In accordance to these considerations, the research is designed as a correlational research based on a survey.

Therefore, with the purpose of developing a theoretically grounded survey, exploratory interviews were first aimed at identifying those more relevant elements for Girona residents, which jointly with an in-depth literature review, were the main inputs for building the questionnaire. Moreover, before distributing the survey, a pilot test was run to assess validity issues. Finally, the survey was distributed and analysed. The research process followed can be seen outlined in Figure 2 .

Interviews were conducted with nine citizens of Girona: three men and six women between the ages of 21 and 71. These interviews were first conceptualized as in-depth and unstructured, then evolved towards semi-structured interviews, and eventually formed the questionnaire in which the survey was based.

The design of the questionnaire was aimed at obtaining high rates of response and at achieving high degrees of validity and reliability. As the questionnaire was distributed in Catalan, Spanish and English, efforts were made to reduce language biases. Since the literature in which the questions are based is in English, the questionnaire was first built in this language. Qualitative interviews were conducted in Catalan, which allowed for checking if interviewees were understanding the meaning of the questions, and if these questions conveyed very similar connotations to each interviewee. However, interviews were not conducted in Spanish, which could contribute to a higher degree of language bias along the survey.

\section{External validity}

External validity refers to the generalizability of the findings (Daniel, 2010b), which means that it examines the extent to which the results obtained will be significative for the whole population of Girona. Considering that the universe for the survey comprises all the adult citizens of Girona, which is 80.093 [calculated from Instituto Nacional de Estadística (2011) and Instituto Nacional de Estadística (2018)], the ideal sampling list would have been the census list of the city, but it was not possible to access it (or any other population list) due to protection policies. Thus, the best alternative was to use a convenience sampling process, which is a type of non-probability sampling process. This was prioritized to obtain enough responses to guarantee external validity and to reduce random error, yet non-probability sampling implies higher probabilities of sampling bias. In addition, it was more pragmatic to distribute the questionnaires only through an online link and through a $\mathrm{QR}$ code, which also contributes to increase sampling biases.

\section{Reliability}

Reliability refers to consistency, which means that after repeating the same test, it will yield the same results (Behar-Horenstein and Dix, 2010). This is one of the reasons why it is important to obtain an adequate number of respondents. On the other hand, the reliability of the measurement scales should also be addressed (Bhattacherjee, 2012; Hair et al., 2013).

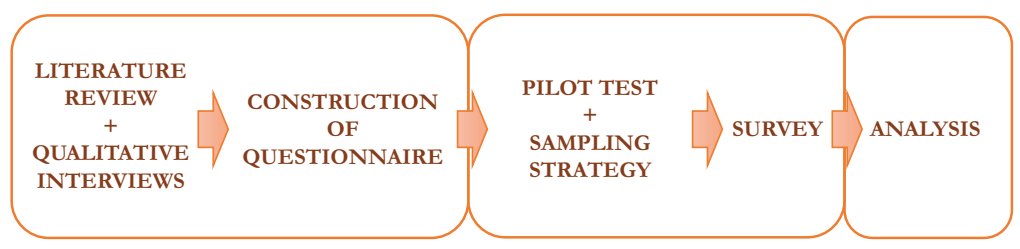

Tourism in the city of Girona 
Five-point scales were used in this research to measure each variable. Given that the constructs analysed were adapted from existing literature, and that most of the studies use Likert-type scales (Gursoy et al., 2002; Gursoy and Rutherford, 2004; Andereck et al., 2007), it seemed reasonable that the same scale was used in this paper.

For an accurate measurement, the anchors of the scales were balanced (Dillman et al., 2008; Bhattacherjee, 2012), and usually ranging from "not at all" to "completely", except for those measuring support towards tourism, as it made more sense to use statements ranging from "strongly disagree" to "strongly agree". Moreover, the option "I do not know" was added for the items measuring the perceived impacts of tourism (both positive and negative). Length of residence was the only indicator that could not be measured using Likert-scales, thus it was measured using five-years intervals scaled question. This design did not work as expected, as it will be explained below.

\section{Validity}

Validity refers to the accuracy of the methods used, which means that validity evaluates the extent to which the methods measure what they are aimed to measure (Daniel, 2010a). The first step to assess validity was to reflexively review literature on residents' attitudes towards tourism and base each of the theoretical constructs on this literature to achieve accurate definitions of each concept. Moreover, the questionnaire was reviewed by a researcher and two Master students.

Exploratory interviews were used to assure that the respondents of the questionnaire would understand all the questions in the same way (or very similar). Moreover, an attention-check question was incorporated in the questionnaire with the purpose to identify those respondents that might be inattentive. Finally, a pilot test was conducted before distributing the survey. However, even if some arrangements were done to ensure the validity of the questions, the pilot test could have been better assessed and more arrangements could have been done before distributing the survey to assure that each construct measured what it was aimed to measure, since some items resulted to be not valid, as it is described in the analysis.

\section{Methods of analysis}

There are extremely sophisticated statistics that one can do, but considering the knowledge on statistics of the researcher, the statistics conducted in this research are simple. Moreover, the results are interpreted in a very careful manner considering the external validity of the data, and because it cannot be assured that the results perfectly describe reality. To assess the data collected using statistical methods, the SPSS software was used.

Factor analysis was used to assess the validity of the scales. Factor analysis is a statistical method used to reduce items into larger variables (latent variables) based on the bi-variate correlations existent between the items (Bhattacherjee, 2012; Baggio and Klobas, 2017). This method was used to check if the items meant to measure a variable were indeed measuring it (validity). In this manner, each item should load at least with a value of 0.5 or more with a latent variable to be considered practically significant (Hair et al., 2013, p. 115).

On the other hand, Cronbach alpha was used to assess the reliability of the scales. Cronbach alpha is a method used to assess the internal consistency of a construct (Bhattacherjee, 2012). It has been generally agreed in statistical research that those Cronbach alpha coefficients greater than 0.7 are internally consistent (Hair et al., 2013, p. 123), thus this is the value used to assess the reliability of the scales.

Finally, bi-variate analyses were run to assess the relationships between each pair of variables. Existing research usually seeks causal relationships between the variables, yet 
this research focuses on correlations and tries to identify possible explanations on the qualitative interviews. A positive relationship exists when the correlation coefficient is positive, and a negative relationship exits when the correlation coefficient is negative. Moreover, the $p$-value expresses the probability that a correlation is caused by chance (Bhattacherjee, 2012). Therefore, $p$-value is used to reject the null hypothesis of no relationship, which is commonly rejected for those $p$-values smaller than 0.005 (Bhattacherjee, 2012). In this study, the discussion is based on those statistically significant relationships, namely those with $p$-values smaller than 0.005 .

Tourism in the city of Girona

\section{Analysis and results}

The data obtained from the survey should be cleansed before doing any kind of analysis. With this purpose, the first lines of this section are aimed at describing how the external validity and the quality of the data were assessed. Afterwards, factor analysis and Cronbach alpha are described, followed by the hypotheses testing process through bi-variate analysis.

The external validity of the data was assessed through the demographic questions included in the survey, which was distributed to 686 people. From these, only 253 completed the questionnaire, which represents a 37 per cent of response rate. Considering that after the factor analysis only 190 questionnaires could be used for the analysis, the sampling error was of \pm 7.1 per cent with a confidence interval of 95 per cent, which is a commonly accepted precision level (Salant and Dillman, 1994). With 83 per cent of respondents aged between 21 and 60 , there seemed to be an underrepresentation of children and elderly people, which could be due to the fact that the survey was addressed to legal adults, and that it was distributed online, which is less accessible for older generations (Dillman et al., 2008). On the other hand, there was an overrepresentation of women (71 per cent) and of some of the neighbourhoods of Girona. These sample errors were consequence of using a nonprobability sampling process, that contributed to give more voice to those citizens who might have more to say, as for example those citizens living in the city Centre, where tourism is much more present than in other neighbourhoods.

Considering the demographics of the sample, it seems that generalization of the results obtained to other populations should be supported with further research, as this sample is not perfectly unbiassed. On the other hand, 229 (90.5 per cent) of the respondents answered the questionnaire in Catalan, which reduced (although not supressed) the potential biases due to language differences, because the questionnaire was built following the inputs from the interviews conducted in Catalan.

To assess the quality of the data, the first step was to convert the answers "I do not know" into missing values in order not to distort the results. Moreover, the survey included an attention-check question to assess the validity of the responses. It had been conceived as follows: "Do you think that Girona should reduce the number of tourists?", which was the opposite to one of the items measuring support towards tourism: "Do you think Girona should attract more tourists?". Thirty-six respondents had answered the same in both questions, whereof twenty-eight had given the neutral answer "I neither agree nor disagree", and which were considered as valid answers. From the eight remaining respondents, six voiced that they disagree with both statements, while two stated to approve both the reduction of tourists and the attraction of more tourists. These eight respondents were analysed individually to identify any erroneous patterns, yet they did not appear to be using uniform patterns nor responding inconsistently, based on the judgement of the researcher. Therefore, it was decided not to modify the database to avoid researcher biases. Moreover, during the qualitative interviews, some of the interviewees expressed contradictory feelings 
regarding to whether there should be more tourists or not. Thus, it was considered as a possible explanation that these eight respondents had contradictory opinions on this matter.

As mentioned above, factor analysis was used to assess the validity of the each variable (Bhattacherjee, 2012; Baggio and Klobas, 2017). However, before conducting the factor analysis, each indicator was briefly examined, and it was observed that "length of residence" was not well constructed and it was not possible to include this important item in the analyses. Moreover, after running an initial factor analysis, it was decided to dismiss the item measuring the frequency of visitation to tourism areas because it was cross loading on more than one factor with rather weak loads and, thus, it was not possible to identify it with any of the latent variables.

After disregarding this item, the factor analysis indicated that six factors (Table II) explained 67,8 per cent of the total variance. However, only 190 respondents from the initial 253 were considered to build the six factors. At first glance, these six factors matched with each of the theoretical block defined in the theoretical framework, which confirmed that they were well constructed. However, two of the items appeared to be loading with a different variable than the one they were expected to. Development of friendship with tourists, seemed to be part of the variable measuring personal benefits instead of involvement in the industry; while the item "I go more to bars and restaurants" aimed at measuring personal benefits was highly correlated with perceived positive impacts instead.

A decision was made to maintain both items. On the one hand, it seemed rational to consider development of friendship as a non-economic personal benefit of tourism. On the other, it was acknowledged above that the lines between personal benefits and community benefits can be blurry, especially for those more social elements. Thus, even if "I go more to bars and restaurants" was meant to measure personal benefits, it was considered that it was still measuring perceived benefits and that it was meaningful to maintain it.

Moreover, the variable measuring involvement in the tourism industry resulted to be not valid. Those items aimed at measuring contact with tourism did not correlate strong enough with the latent variable, while the correlation between participating in the tourism decisionmaking process and the latent variable was rather weak. Thus, it seems that the variable mainly measured knowledge about tourism. However, the strong correlation between being participative and knowledgeable should not be underestimated as it shows how these two concepts go together most of the time and that a broader construct can be built based on them.

Cronbach alpha was the reliability measure used to assess the internal consistency of these variables. Each of the six coefficients analysed were higher than 0.7 , which verified their reliability (Hair et al., 2013, p. 123).

Once the validity and reliability of each of the variables was reviewed, the distribution of each of them was briefly examined to obtain a general overview of which might be the attitudes held by the residents of Girona regarding tourism. However, this is a very simple summary, especially considering that the sample was not completely unbiased, and that reality cannot be perfectly known. In this line, the distributions were analysed in terms of kurtosis, to assess whether the values were concentrated or dispersed; and skewness, to assess if the distribution was tailed or not, and in which direction (Hair et al., 2013). Table III exhibits both indicators for all the variables analysed.

The distribution of support towards tourism (Figure 3) shows that most residents are rather supportive towards tourism, as values are very concentrated (kurtosis of 1.414) towards the right of the graph (median of 0.14), while a negative tail (skewness of -0.866) indicates that few residents are very opposed to its development. Looking back at the factor analysis, support towards tourism is very much defined by those more quantifiable aspects, 


\begin{tabular}{|c|c|c|c|c|c|c|c|}
\hline \multirow[b]{2}{*}{ Rotated component matrix ${ }^{a}$} & \multirow[b]{2}{*}{1} & \multirow[b]{2}{*}{2} & \multicolumn{2}{|c|}{ Component } & \multirow[b]{2}{*}{5} & \multirow[b]{2}{*}{6} & \multirow{2}{*}{$\begin{array}{l}\text { Tourism in the } \\
\text { city of Girona }\end{array}$} \\
\hline & & & 3 & & & & \\
\hline SUPPORT - IMP. IND. & 0.973 & & & & & & \\
\hline SUPPORT - IMP. ROLE & 0.875 & & & & & & \\
\hline SUPPORT - HELPS GROW & 0.836 & & & & & & \\
\hline SUPPORT - PROUD OF TOURISTS COMMING & 0.747 & & & & & & \\
\hline SUPPORT - SUPPORT DEVELOP. & 0.607 & & & & & & 175 \\
\hline SUPPORT - SHOULD ATTRACT MORE T. & 0.557 & & & & & & \\
\hline SUPPORT - GROW IN RIGHT DIR. & 0.541 & & & & & & \\
\hline BENEFITS - OPP. LEISURE & & 0.880 & & & & & \\
\hline BENEFITS - MORE EMPLOY. & & 0.813 & & & & & \\
\hline BENEFITS - OPP. BUSINESS & & 0.777 & & & & & \\
\hline BENEFITS - OPP. SOCIALIZING & & 0.684 & & & & & \\
\hline PERSONAL B. - MORE BARS AND REST. I CAN GO & & 0.679 & & & & & \\
\hline BENEFITS - APPEARANCE & & 0.532 & & & & & \\
\hline COSTS - NOISES & & & 0.939 & & & & \\
\hline COSTS - POLLUTION & & & 0.921 & & & & \\
\hline COSTS - CONGESTIONS & & & 0.856 & & & & \\
\hline COSTS - INC. RENTS & & & 0.671 & & & & \\
\hline COSTS - ESTABLISHMENTS FOR TOURISTS & & & 0.529 & & & & \\
\hline COSTS - INCR. GOODS\&SERVICES & & 0.429 & 0.522 & & & & \\
\hline INV. - KNOW. TOURISTS IN G & & & & 0.850 & & & \\
\hline INV.- KNOW. T. DEVELOP. & & & & 0.843 & & & \\
\hline INV. - KNOW. POSSIBLE IMPACTS & & & & 0.805 & & & \\
\hline INV.- DEC. MAK. PROCESSES & & & & 0.517 & 0.417 & & \\
\hline PERSONAL B. - I HAVE A JOB & & & & & 0.773 & & \\
\hline PERSONAL B. - MY INCOME DERIVES FROM T. & & & & & 0.771 & & \\
\hline INV. - CONTACT-FRIENDSHIP & & & & & 0.667 & & \\
\hline PERSONAL B. - MEET PEOPLE and LEARN CULTURES & & & & & 0.625 & & \\
\hline ATTACH. - F. OF MOVING & & & & & & 0.847 & \\
\hline ATTACH. - I FEEL AT HOME & & & & & & 0.785 & Table II. \\
\hline ATTACH. - INTEREST & & & & & & 0.684 & Dimension loadings \\
\hline $\begin{array}{l}\text { Notes: Extraction method: principal components analys } \\
\text { normalization }{ }^{\text {a }}{ }^{\text {Rotation converged in } 9} \text { iterations }\end{array}$ & sis; $r$ & ation & nethod: & Promax & with & Kaiser & $\begin{array}{l}\text { produced by the } \\
\text { factor analysis }\end{array}$ \\
\hline
\end{tabular}

especially those relating to economic growth in the city. These findings support the idea that it is easier for citizens to identify the economic aspects of tourism than the social ones; and thus, it is suggested that there is space to enhance the relevance of the later.

Relating to the tourism impacts perceived by residents, it seems like opinions are diverse in both the negative impacts perceived and the positive ones (kurtosis of benefits is -0.3 ; while kurtosis of costs is -0.158 ). Moreover, both cases show a negative tail (skewness of benefits is -0.188 ; while skewness of costs is -0.08 ) which means that few cases perceive very little (or no) benefits from tourism, while few other cases perceive very little (or no)

\begin{tabular}{|c|c|c|c|c|c|c|c|}
\hline & FA2_SUPPORT & FA2_BENEFITS & FA2_COSTS & FA2_INV & FA2_PB & FA2_ATTACH & Table III. \\
\hline $\begin{array}{l}\text { Median } \\
\text { Skewness } \\
\text { Kurtosis }\end{array}$ & $\begin{array}{l}0.1400272 \\
-0.866 \\
1.414\end{array}$ & $\begin{array}{l}0.0009623 \\
-0.188 \\
-0.300\end{array}$ & $\begin{array}{l}-0.0361121 \\
-0.080 \\
-0.158\end{array}$ & $\begin{array}{l}-0.1270571 \\
0.353 \\
-0.064\end{array}$ & $\begin{array}{l}-0.1060703 \\
0.700 \\
0.244\end{array}$ & $\begin{array}{l}0.1543804 \\
-0.508 \\
-0.142\end{array}$ & $\begin{array}{r}\text { Median, skewness } \\
\text { and kurtosis values } \\
\text { for each construct }\end{array}$ \\
\hline
\end{tabular}


Figure 3.

Distribution of support towards tourism

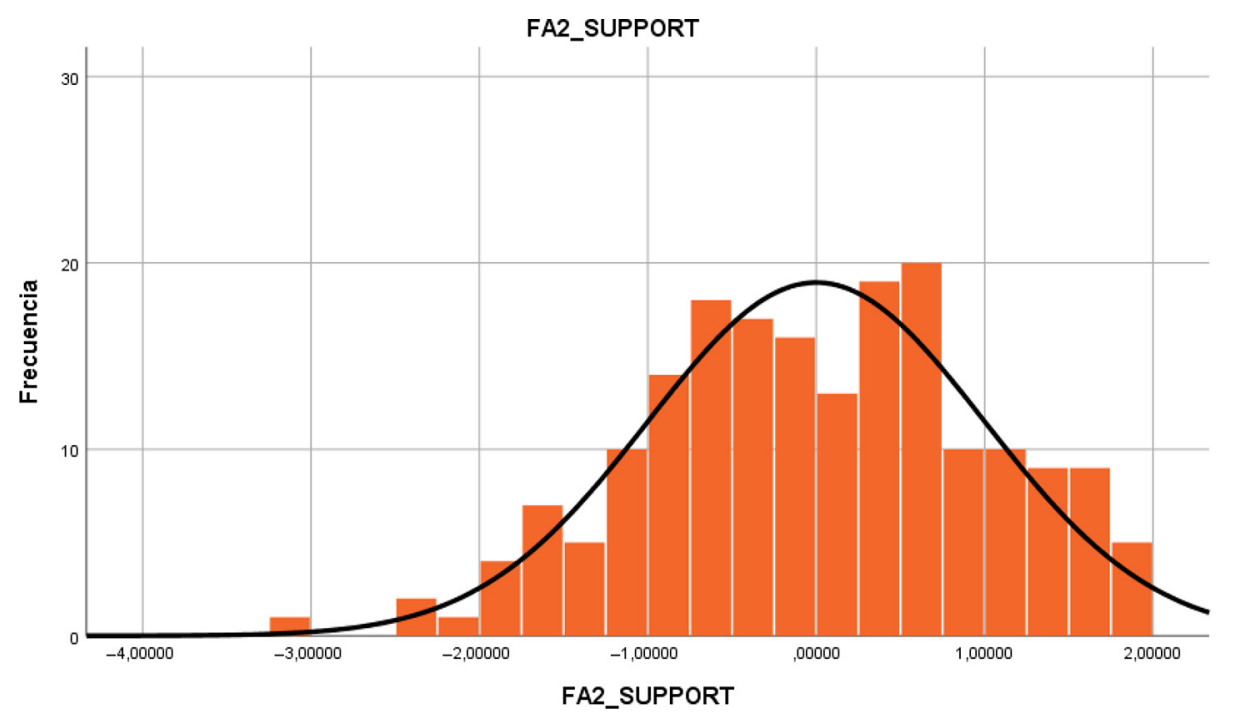

negative impacts from tourism in their communities. On the other hand, the distribution of involvement in the tourism industry points that most residents in Girona do not feel very knowledgeable about the tourism activity in their city, except from few cases who consider themselves very well informed about it (skewness of 0.353 ).

Concerning the distribution of personal benefits derived from tourism, it is tailed towards the right (skewness of 0.7) and very concentrated (kurtosis of 0.244), which indicates how only few citizens consider that they personally benefit from tourism. Considering how difficult it was for some interviewees to think of a personal non-economic benefit that they could derive from tourism, it makes sense that this distribution is positively tailed. Moreover, it highlights the idea that those non-economic personal benefits could be further widened.

Finally, the distribution of the variable measuring attachment to communities is tailed towards the left $(-0.508)$ and rather flat $(-0.142)$, which means that even if feelings of attachment are diverse among the respondents, they tend to feel attached to their communities. Moreover, the disperse results could be caused by the dismissal of the item measuring length of residence.

As already mentioned, this is just a very simple description of which might be the opinions held by residents of Girona relating to tourism. In the following lines, the relationships between each of the variables just described are examined through bivariate analyses. Table IV shows the correlations found between each of the variables, as well as its $p$-value.

This table displays a strong positive and significant relationship $(0.608 ; p=0.00)$ between perceived benefits from tourism and support towards it; as well as it indicates a negative and significant relationship $(-0.411 ; p=0.00)$ between perceived costs of tourism and support towards it. Personal benefits appear to be positively related with perceived benefits $(0.366 ; p=0.00)$ and negatively related with perceived costs $(-0.321 ; p=0.00)$. On the other hand, attachment to communities show a weak positive relationship with perceived benefits from tourism $(0.171 ; p<0.018)$, and no significant relationship with perceived costs $(p>0.05)$. However, being involved in the industry (measured mainly through knowledge about tourism) appears to have a statistically significant relationship 


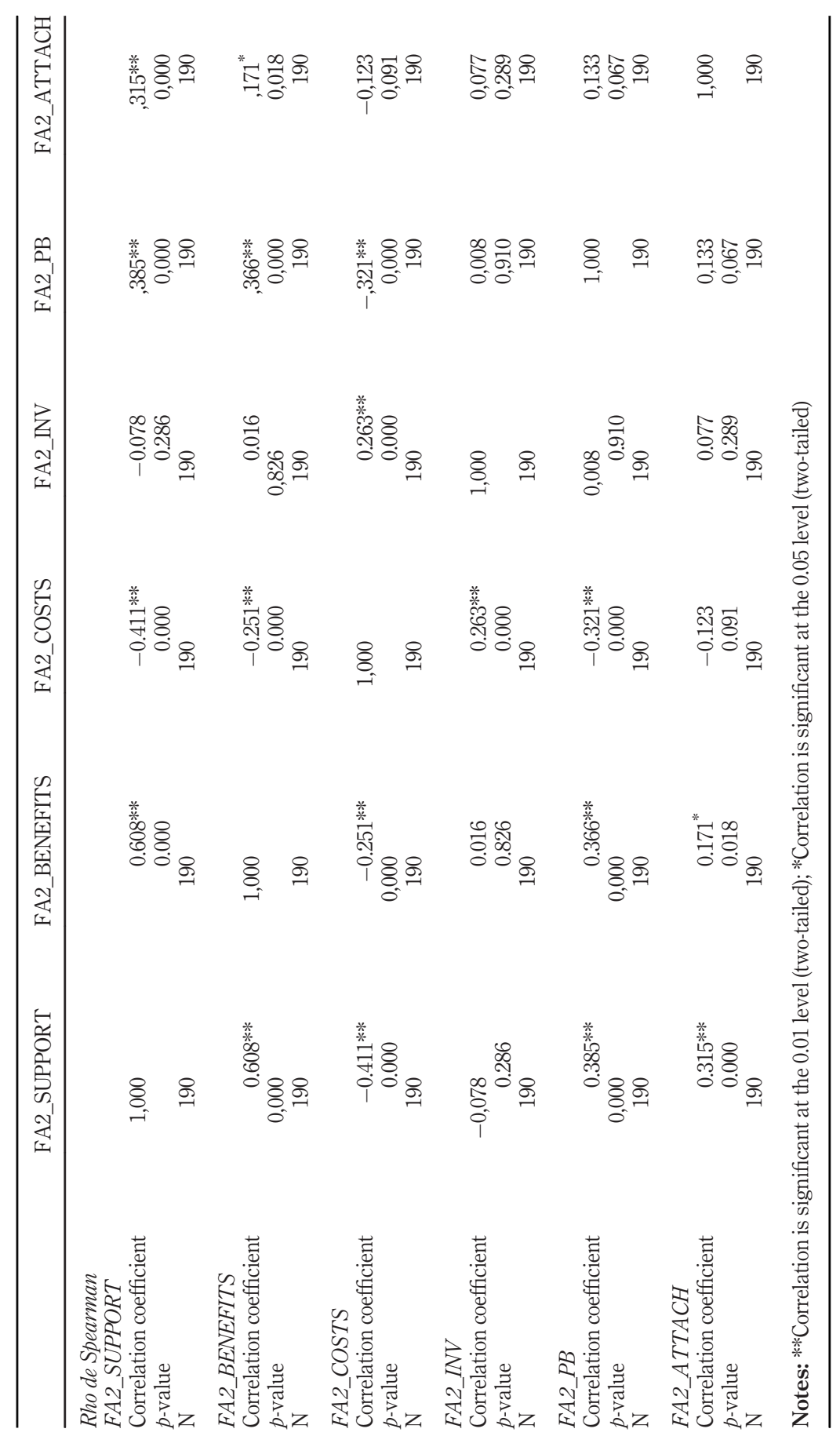

Tourism in the city of Girona

Table IV. Correlation coefficients between the constructs, and $p$-values, resulting from the bivariate analysis 
JTA

27,2

\section{8}

\section{Figure 4.}

Statistically

significant

correlations between

variables only with perceived costs, and it is a positive relationship $(0.263, p=0.00)$, which is the opposite of what was expected.

Finally, three new relationships are found: personal benefits from tourism show a direct positive relationship with support towards tourism $(0.385 ; p<0)$; attachment to communities also exhibits a direct positive relationship with support towards tourism $(0.315 ; p .<0)$; and a significant negative relationship is found between perceived positive impacts and perceived negative impacts $(-0.251 ; p=0.00)$, which could be suggesting that those citizens that are more aware of the benefits of tourism may tend not to perceive the negative ones, and the other way around.

These relationships are plotted in Figure 4 and discussed in the following, with the support of the inputs from the qualitative interviews and from the literature review.

\section{Discussion}

Research based on statistics is often aimed at finding causality between variables that can next lead to forecasts. However, this research is based on correlations, which is insufficient to claim a causal relationship, and thus the results are presented with arrows going both ways, as it can be seen in Figure 4 . While causality implies that one variable causes the other, correlations simply state that two variables are related somehow, but it does not provide with an explanation why they are related or if there are causal relationships between them (Bhattacherjee, 2012). Hence, discussions are based on the correlations found and causal relationships are not derived from the results of the survey, yet interviews are used to understand which possible explanations could be behind the relationships found.

Figure 4 summarises those statistically significant relationships found on the bivariate analyses. Previous literature had found statistically significant relationships between benefits and support towards tourism (Gursoy and Rutherford, 2004; Nunkoo and So, 2016; Perdue et al., 1990) yet, no statistically significant relationships between costs and support towards tourism (Gursoy et al., 2002; Nunkoo and So, 2016). In this study, however, both relationships appear to be significant, which indicates that citizens of Girona might be more concerned about the costs of tourism than other communities. During the qualitative interviews, when interviewees were asked about the costs of tourism, they tended to compare the situation in Girona with those experienced in close tourism destinations, such as Costa Brava or Barcelona. This suggested that the closeness of Girona to very touristic destinations could raise the awareness of tourism costs. This indicates that there could be a third factor, the perceived costs of tourism in close tourism destinations (where most citizens

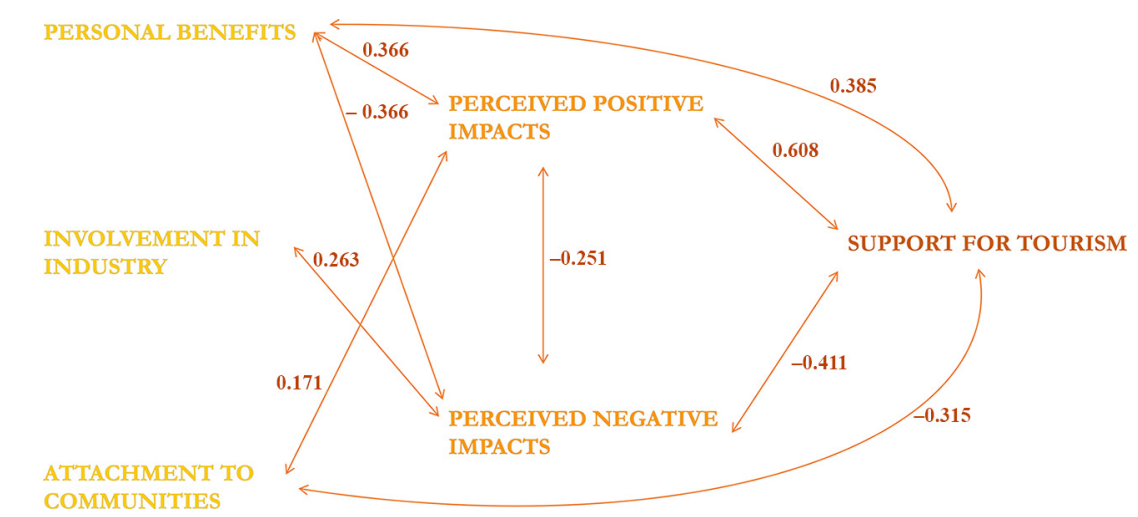


usually go or have lived, for example), affecting this relationship. Hence, for example, it could be that perceived costs in close tourism destinations was an intermediate variable between costs perceived in the residents' destinations and support towards tourism, which could explain why the relationship is statistically significant in this study.

\section{Benefits of friendship}

Apart from the influence that perceived costs and perceived benefits have on support towards tourism, this thesis also analyses the influence that personal benefits derived from tourism, involvement in the industry, and attachment to communities could have on these perceptions. The resulting relationships between personal benefits and perceived impacts from tourism seem to align with existing literature (Andereck et al., 2005; Perdue et al., 1990), as it positively correlated with positive impacts and negatively correlated with negative impacts. Moreover, personal benefits directly correlated with support towards tourism, which was also found in previous studies (Nunkoo and So, 2016; Perdue et al., 1990). These results support literature on the importance that deriving personal benefits from tourism has on being supportive towards it, however it tries to go beyond economic benefits as it also aims at including those personal benefits that are more social or cultural.

While existing literature usually focus on economic personal benefits (Andereck et al., 2005; Jurowski et al., 1997), this research shows that the degree to which residents learn from other cultures thanks to tourism or their level of friendship with tourists could be used to measure those non-economic personal benefits. During the interviews, some interviewees expressed their lack of interaction with tourists, which suggests that there could be space for increasing personal benefits that citizens derive from tourism through boosting interactions between tourists and residents.

Friendship (with residents) is an item that has been used to measure different variables, such as attachment to communities (Gursoy et al., 2002; Hummon, 1992) or quality of life (Andereck and Nyaupane, 2011). In fact, friendship can be defined as "one attached to another by affection or esteem" (Merriam-Webster, 2018b), but it also means "one that is not hostile" (Merriam-Webster, 2018a). Considering one of the main aims for researchers to study attitudes towards tourism is to avoid "hostile" behaviours, it seems that the role of friendship could be further researched as an element of personal benefits derived from tourism. Other authors have also stressed the importance of friendship with non-residents, as for example Lindberg and Johnson (1997), who considered it a core value. However, it is not generally included as a personal benefit in studies within SET frameworks, which could contribute to expanding the concept of personal benefits towards including more emotional values.

\section{Importance of knowledge}

As already explained, the variable on involvement in the tourism industry was not valid, and it resulted to be measuring mainly knowledge about tourism and participation in the decision-making process. If one focuses on knowledge, the findings obtained suggest that residents perceive similar levels of benefits from tourism regardless the knowledge they have about the industry, and that those more knowledgeable perceive higher levels of negative impacts than the rest. These findings are aligned with Nunkoo and So (2016), but they seem to contradict other authors such as Andereck et al. (2005) or Davis et al. (1988). This is not surprising considering that these studies use different scales to measure knowledge and that the scale used in this research is adapted from Nunkoo and So (2016). Yet, based on these results, a clear relationship exists between knowledge about tourism and perceived costs. During the qualitative interviews, those who had weaker opinions, or non- 
opinions at all, specially relating to the negative impacts, were those who considered that they did not know much about tourism. Thus, a possible explanation for this relationship could be that those less knowledgeable residents are aware about the benefits of tourism but not very informed about its negative impacts.

On the other hand, the fact that being participative in the decision-making process was positively related with perceived negative impacts and not significatively related with perceived positive impacts contradicts previous research on this topic (Andereck et al., 2005; Lankford and Howard, 1994; Nunkoo and So, 2016). Based on the qualitative interviews it could be argued that those who do not perceive negative impacts, do not feel the need to participate. On the other hand, those more participative interviewees complained that their opinions were not being listened to. These complaints could be indicating the possibility of a third factor influencing respondents' attitudes. For example, trust with the government could be influencing the relationship between being participative and negative impacts about tourism, yet research should be done to assess these relationships.

Considering that correlations do not imply causality, the fact that knowledge and participation in the decision-making process are positively related with costs could be implying that those more critical about tourism are more knowledgeable and participative, which could be considered as a good situation to lead towards a more sustainable tourism development. In addition, the interviews point that there could be some space for improving citizens' trust towards their government, which could substantively add to this movement towards social sustainability.

\section{Those feelings of proudness}

Existing literature on attachment to communities found positive relationships between attachment and perceived positive impacts, and no significant relationship between attachment and perceived negative impacts (Andereck et al., 2005; Gursoy et al., 2002; Gursoy and Rutherford, 2004), which seems to be perfectly aligned with the findings of this research, as the same relationships were found. Moreover, a direct relationship was found between attachment to communities and support towards tourism, which is also found by other authors (Gursoy and Rutherford, 2004). Attachment to communities could be considered the least directly related to tourism variable analysed within this research (compared to personal benefits from tourism and involvement in the tourism industry), and yet these findings stress the importance that it has on support towards tourism.

Some authors suggest that those more attached citizens tend to be more supportive because they want to see their communities progress and they see how tourism can play a key role for this growth (Andereck et al., 2005). During the qualitative interviews, not only this tendency could be perceived, but it was also felt that those attached residents tended to express higher levels of proudness of receiving tourism in Girona. Except for one interviewee, those who expressed that they would feel sad if they had to move out voiced how tourism increased their proudness of Girona, as they felt that the city was being more recognized and valued thanks to tourism. Therefore, the direct relationship between attachment to communities and support towards tourism could go beyond willing the city to prosper and refer as well to feelings and emotions such as the proudness generated by tourists willing to visit Girona. Considering that several authors have analysed both proudness of being from a place or destination as a measure for attachment (Hummon, 1992; Williams and Lawson, 2001), and increased proudness of a place thanks to tourism as a measure of support (Nunkoo and So, 2016; Tovar and Lockwood, 2008), it seems that literature supports the key role that proudness has for those attached citizens to support tourism. 


\section{Conclusions and reflections}

To conclude, few lines are aimed at reflecting on how this research has been developed as well as how it could be useful for management decisions and how it contributes to existing knowledge on attitudes towards tourism. In this line, even though this research aims at being objective, the subjectivity of the researcher could have biased the results, especially considering that the answers as to why the resulting relationships arose were (partially) based on the qualitative interviews. Moreover, more sophisticated statistics could have been run with the data collected, and further results could have been obtained. Yet, as already mentioned, the limited knowledge on statistics of the researcher set the boundaries of the statistical analyses. Considering the external validity of the data and the fact that reality cannot be perfectly known, it is not assured that the results represents the whole population of Girona; as well as the discussion does not try to extrapolate any of the results to other urban destinations because they are time and context bounded (data was collected in Girona in May 2018).

The aim of this research was to describe the attitudes of the residents of Girona towards tourism and to develop a deeper understanding on elements related to tourism that may be more likely to influence these attitudes. Hence, the research question was the following:

$R Q 1$. How do residents of Girona perceive tourism? And what are the possible reasons behind these perceptions?

One of the main purposes of this study was to move towards enhancing those emotional components within a SET theoretical framework, which is in line with other authors (Williams and Lawson, 2001; Boley et al., 2014; Woosnam and Norman, 2009) that tried to focus on less rational elements. Therefore, and even if this is a correlational research, qualitative interviews were essential to understanding which emotional elements might be key to explaining some of the relationships found.

Results suggest that, overall, residents of Girona do support tourism development and that they perceive its benefits. Yet, it is also found that they might be more critical about the negative impacts of tourism than other communities, especially those more knowledgeable and participative citizens. On the other hand, those who personally benefit from tourism and those more attached to their communities appeared to be very supportive towards tourism.

Relating to the managerial implications, it seems that citizens are missing more quality contact with tourists which highlights that promoting more spaces of interaction between residents and tourists could be beneficial. On the other hand, the authenticity of Girona should never be neglected, but rather advocated, since it could contribute to increase those feelings of proudness that make citizens be more willing to host tourists.

This research also adds to the current understanding of attitudes towards tourists within SET framework, especially relating to covering those more emotional elements, as it is suggested that friendship with tourists could be a good measurement for personal benefits; that proudness could be a possible explanation for the positive relationship between attachment and support; and that costs in close popular tourism destinations could intensify the relationship between perceived costs of tourism and the support towards it. Moreover, this study contributes in generating knowledge about those small urban destinations that seem to be neglected by existing literature.

\section{Note}

1. Instituto Nacional de Estadística (INE) is the Spanish National Institute of Statistics. 


\section{References}

Andereck, K.L. and Nyaupane, G.P. (2011), "Exploring the nature of tourism and quality of life perceptions among residents", Journal of Travel Research, Vol. 50 No. 3, pp. 248-260.

Andereck, K.L., Valentine, K.M., Knopf, R.C. and Vogt, C.A. (2005), "Residents' perceptions of community tourism impacts", Annals of Tourism Research, Vol. 32 No. 4, pp. 1056-1076.

Andereck, K.L., Valentine, K.M., Vogt, C.A. and Knopf, R.C. (2007), "A cross-cultural analysis of tourism and quality of life perceptions", Journal of Sustainable Tourism, Vol. 15 No. 5, pp. 483-502.

Baggio, R. and Klobas, J. (2017), Quantitative Methods in Tourism, 2nd edn, in Cooper, C, Hall, C.M. and Timothy, D.J. (Eds), Channel view publications, Bristol.

Behar-Horenstein, S. and Dix, A.C. (2010), "Reliability”, in Kridel, C. (Ed.), Encyclopedia of Curriculum Studies, Sage Publications, Thousands Oaks, CA, pp. 739-740.

Bellini, N. and Pasquinelli, C. (2017), Tourism in the City: Towards an Integrative Agenda on Urban Tourism, in Bellini, N. and Pasquinelli, C. (Eds), Springer, New York, NY.

Bhattacherjee, A. (2012), "Social science research: principles, methods, and practices", Textbooks Collection.

Boley, B.B., McGehee, N.G., Perdue, R.R. and Long, P. (2014), "Empowerment and resident attitudes toward tourism: Strengthening the theoretical foundation through a Weberian lens", Annals of Tourism Research, Vol. 49, pp. 33-50.

Brunt, P. and Courtney, P. (1999), "Host perceptions of social cultural impacts", Annals of Tourism Research, Vol. 26 No. 3, pp. 493-515.

Burgen, S. (2017a), "Barcelona anti-tourism activists vandalise bikes and bus", The Guardian, available at: www.theguardian.com/world/2017/aug/01/barcelona-anti-tourism-activists-vandalise-bikes-and-bus

Burgen, S. (2017b), "Barcelona marches to curb negative effects of tourism boom", The Guardian, available at: www.theguardian.com/world/2017/jan/29/barcelona-residents-protest-high-rentsfuelled-by-tourism

Carreras, J. and Pastells, J. (2017), "Volen que airbnb només ofereixi pisos legals [they want that airbnb only offers legal apartments]", Ara, 20 July, available at: www.ara.cat/comarquesgironines/ Volen-Airbnb-nomes-ofereixi-legals_0_1835816450.html

Coldwell, W. (2017), "First Venice and Barcelona: now anti-tourism marches spread across Europe", The Guardian, available at: www.theguardian.com/travel/2017/aug/10/anti-tourism-marchesspread-across-europe-venice-barcelona

Daniel, L.G. (2010a), “Validity, construct/content”, in Kridel, C. (ed.) Encyclopedia of Curriculum Studies, Sage Publications, Thousands Oaks, CA:pp. 924-925.

Daniel, L.G. (2010b), "Validity, external/internal”, in Kridel, C. (ed.) Encyclopedia of Curriculum Studies, Sage Publications, Thousands Oaks, CA, pp. 926-926.

Davis, D., Allen, J. and Cosenza, R.M. (1988), "Segmenting local residents by their attitudes, interests, and opinions toward tourism", Journal of Travel Research, Vol. 27 No. 2, pp. 2-8.

Deery, M., Jago, L. and Fredline, L. (2012), "Rethinking social impacts of tourism research: a new research agenda", Tourism Management, Vol. 33 No. 1, pp. 64-73.

Dillman, D.A., Smyth, J.D. and Christian, L.M. (2008), Internet, Mail, and Mixed-Mode Surveys: The Tailored Design Method, 3rd edn., John Wiley and Sons, Hoboken.

Dunne, G., Buckley, J. and Flanagan, S. (2007), "City break motivation: the case of Dublin- a successful national Capital", Journal of Travel and Tourism Marketing, Vol. 22 Nos 3/4, pp. 95-107.

European Cities Marketing (2018), "The european cities marketing benchmarking report 14th official edition", Dijon.

Gursoy, D. and Rutherford, D.G. (2004), "Host attitudes toward tourism: an improved structural model", Annals of Tourism Research, Vol. 31 No. 3, pp. 495-516. 
Gursoy, D., Jurowski, C. and Uysal, M. (2002), "Resident attitudes”, Annals of Tourism Research, Vol. 29 No. 1, pp. 79-105.

Hair, J.F., Black, W.C., Babin, B.J. and Anderson, R.E. (2013), Multivariate Data Analysis: Pearson New International Edition, Seventh.: Pearson Education, Harlow.

Hummon, D.M. (1992), Community Attachment: Local Sentiment and Sense of Place in Place Attachment', in Altman, I. and Low, S.M. (Eds), Plenum Press, New York, NY, pp. 253-278.

Instituto Nacional de Estadística (2011), "Censos de población y viviendas 2011, Resultados municipales [population and housing census 2011. Municipal results]”.

Instituto Nacional de Estadística [National Statistics Institute (2018), "Cifras oficiales de población resultantes de la revisión del padrón municipal a 1 de enero [official figures of the population resulting from the revision of the municipal census on the 1th of January]", available at www.ine. es/jaxiT3/Datos.htm?t=2911

Jurowski, C., Uysal, M. and Williams, D.R. (1997), “A theoretical analysis of host community resident reactions to tourism", Journal of Travel Research, Vol. 36 No. 2, pp. 3-11.

Kayat, K. (2002), "Power, social exchanges and tourism in Langkawi: rethinking resident perceptions", International Journal of Tourism Research, Vol. 4 No. 3, pp. 171-191.

Kettle, M. (2017), "Mass tourism is at at tipping point - but we're all part of the problem”, The Guardian. available at: www.theguardian.com/commentisfree/2017/aug/11/tourism-tipping-point-travelless-damage-destruction

Lankford, S.V. and Howard, D.R. (1994), "Developing a tourism impact attitude scale", Annals of Tourism Research, Vol. 1, pp. 121-139.

Law, C.M. (1992), "Urban tourism and its contribution to economic and image regeneration", Urban Studies, Vol. 29 No. 3-4, pp. 599-618.

Lindberg, K. and Johnson, R.L. (1997), "Modeling resident attitudes toward tourism", Annals of Tourism Research, Vol. 24 No. 2, pp. 402-424.

McCool, S.F. and Lime, D.W. (2001), "Tourism carrying capacity: tempting fantasy or useful reality?", Journal of Sustainable Tourism, Vol. 9 No. 5, pp. 372-388.

McCool, S.F. and Martin, S.R. (1994), "Community attachment and attitudes toward tourism development", Journal of Travel Research, Vol. 32 No. 3, pp. 29-34.

Merriam-Webster (2018a), "Friendship' [def. 2]", available at: www.merriam-webster.com/dictionary/ friends

Merriam-Webster (2018b), "Friendship' [def.1]", available at: www.merriam-webster.com/dictionary/ friends

Moscardo, G. (2011), "Exploring social representations of tourism planning: Issues for governance", Journal of Sustainable Tourism, Vol. 19 Nos 4/5, pp. 423-436.

Nunkoo, R. and So, K.K.F. (2016), "Residents' support for tourism: Testing alternative structural models", Journal of Travel Research, Vol. 55 No. 7, pp. 847-861.

Pastells, J. (2017) "Alerta per la proliferació de pisos turístics a Girona [alert of ploriferation of toursim apartments in Girona]", Ara. Girona, available at: www.ara.cat/comarquesgironines/Alertaproliferacio-pisos-turistics_0_1793820602.html (accessed 11 December 2017).

Perdue, R.R., Long, P.T. and Allen, L. (1990), "Resident support for tourism development", Annals of Tourism Research, Vol. 17 No. 4, pp. 586-599.

Pizam, A. (1978), "Tourism's impacts: the social costs to the destination community as perceived by its residents", Journal of Travel Research, Vol. 16 No. 4, pp. 8-12.

Ratner, C. (2012), "Reductionism”, in Given, L.M. (Ed.), The SAGE Encyclopedia of Qualitative Research Methods, Sage Publications. Thousand Oaks.

Salant, P. and Dillman, D.A. (1994), How to Conduct Your Own Survey, John Wiley and Sons, New York, NY. 
Su, L., Huang, S. and Huang, J. (2018), "Effects of destination social responsibility and tourism impacts on residents 'rupport for tourism and perceived quality of life", Journal of Hospitality and Tourism Research, Vol. 42 No. 7, pp. 1039-1057.

Tosun, C. (2002), "Host perceptions of impacts.pdf", Annals of Tourism Research, Vol. 29 No. 1, pp. 231-253.

Tovar, C. and Lockwood, M. (2008), "Social impacts of tourism: an Australian regional case study", International Journal of Tourism Research, Vol. 10 No. 4, pp. 365-378.

Valls, J.F., Sureda, J. and Valls-Tuñon, G. (2014), “Attractiveness analysis of European tourist cities", Journal of Travel and Tourism Marketing, Vol. 31 No. 2, pp. 178-194.

Walle, A.H. (1997), "Quantitative versus qualitative tourism research", Annals of Tourism Research, Vol. 24 No. 3, pp. 524-536.

Williams, J. and Lawson, R. (2001), "Community issues and resident opinions of tourism”, Annals of Tourism Research, Vol. 28 No. 2, pp. 269-290.

Woosnam, K.M. and Norman, W.C. (2009), "Exploring the theoretical framework residents and tourists", Journal of Travel Research, Vol. 48 No. 2, pp. 245-258.

World Tourism Organization (2018), UNWTO Tourism Highlights, World Tourism Organization, Madrid.

World Travel and Tourism Council (2018), "Travel and tourism economic impact 2018 world”, London.

\section{Corresponding author}

Sira Vidal Rua can be contacted at: siravr@gmail.com

For instructions on how to order reprints of this article, please visit our website: 